\title{
High-Strength Suture Tapes Are Biomechanically Stronger Than High-Strength Sutures Used in Rotator Cuff Repair
}

\author{
Paul Borbas, M.D., Lukas Fischer, B.Sc., Lukas Ernstbrunner, M.D., Ph.D., \\ Armando Hoch, M.D., Elias Bachmann, M.Sc., Samy Bouaicha, M.D., and Karl Wieser, M.D.
}

\begin{abstract}
Purpose: To assess the mechanical properties, tendon resistance to suture cutout, and knot size of a broad variety of highstrength sutures and tapes available for arthroscopic rotator cuff repair. Methods: Nine different types of high-strength sutures and tapes for arthroscopic rotator cuff repair were studied: 6 were tapes (FiberTape, Hi-Fi Tape, Permatape, SutureTape, UltraTape, and XBraid TT), and 3 were sutures (Dynacord, FiberWire, and Ultrabraid). First, mechanical tensile testing of suture loops $(\mathrm{n}=6)$ was performed. Second, the suture material was passed through an intact human cadaveric rotator cuff tendon (supraspinatus or infraspinatus), and cyclic as well as load-to-failure testing was performed, 8 times for each suture or tape. Statistical analysis of groups (tapes vs sutures) and between each suture and each tape was performed. Results: Material testing revealed significant differences with superior mechanical properties of tapes compared with sutures regarding load for $3 \mathrm{~mm}$ of displacement ( $201 \mathrm{~N}$ vs $84 \mathrm{~N}, P<.0001$ ), displacement at $200 \mathrm{~N}$ ( $3.6 \mathrm{~mm}$ vs $6.6 \mathrm{~mm}$, $P<.0001$ ), stiffness $(46 \mathrm{~N} / \mathrm{mm}$ vs $25 \mathrm{~N} / \mathrm{mm}, P<.0001)$, and ultimate load to failure ( $509 \mathrm{~N}$ vs $288 \mathrm{~N}, P<.0001$ ). FiberTape showed the highest ultimate load to failure $(805.5 \pm 36.1 \mathrm{~N})$, the highest load necessary for $3 \mathrm{~mm}$ of displacement $(376.2 \pm 19.1$ $\mathrm{N})$, and the lowest displacement at a $200-\mathrm{N}$ load $(2 \pm 0.1 \mathrm{~mm})$. Permatape had the highest stiffness $(58.5 \pm 5.3 \mathrm{~N} / \mathrm{mm})$. FiberTape had the highest knot height $(9.5 \pm 1.3 \mathrm{~mm})$ and knot width $(3.8 \pm 0.7 \mathrm{~mm})$ of a suture loop with 7 square knots. The typical failure mode in the cadaveric study part was tendon cut through. Conclusions: Biomechanical in vitro testing showed that high-strength suture tapes compared with regular high-strength sutures have significantly better mechanical properties in both dry-laboratory testing and human cadaveric rotator cuff tendon pullout testing. FiberTape outperformed the other tapes and the sutures used in this analysis. Nonetheless, differences in tendon testing appeared to be less substantial than in drylaboratory testing, and FiberTape had the highest knot height and width. Clinical Relevance: FiberTape revealed the most favorable biomechanical performance in dry-laboratory and rotator cuff tendon testing. It may provide the best repair strength in vivo; however, it also has the largest knot size.
\end{abstract}

S uccessful tendon-to-bone healing in rotator cuff repair (RCR) relies on several important factors, including adequate blood supply and bone quality, as

From the Department of Orthopaedics, Balgrist University Hospital, Zurich, Switzerland (P.B., L.F., L.E., A.H., S.B., K.W.); and Institute of Biomechanics, ETH Zurich, Zurich, Switzerland (E.B.).

The authors report the following potential conflicts of interest or sources of funding: S.B. receives royalties from Arthrex, outside the submitted work. Full ICMJE author disclosure forms are available for this article online, as supplementary material.

Received September 10, 2020; accepted January 30, 2021.

Address correspondence to Paul Borbas, M.D., Department of Orthopaedics. Balgrist University Hospital, Forchstrasse 340, 8008 Zurich, Switzerland. E-mail:paul.borbas@balgrist.ch

(C) 2021 THE AUTHORS. Published by Elsevier Inc. on behalf of the Arthroscopy Association of North America. This is an open access article under the CC BY-NC-ND license (http://creativecommons.org/licenses/by-nc-nd/4.0/). 2666-061X/201513

https://doi.org/10.1016/j.asmr.2021.01.029 well as tendon and muscle quality. ${ }^{1-4}$ Since the breakthrough of arthroscopic RCR (aRCR), technical factors and material properties have gained more importance. ${ }^{5,6}$ Correct stitch positioning, suture configuration, and adequate knot-tying techniques have been proved prerequisites for successful aRCR. ${ }^{7-10}$ Failure analyses suggest that the suture-tendon interface is the weakest link of aRCR constructs. ${ }^{11,12}$

Historically, No. 2 Ethibond (Ethicon, Somerville, NJ), which is a braided, nonabsorbable polyester suture, had been used as a standard suture. ${ }^{6,13}$ Over time, polyblend suture materials that incorporate ultrahigh-molecularweight polyethylene (UHMWPE) were introduced and gained popularity because of their biomechanical superiority. ${ }^{6,14}$ FiberWire (Arthrex, Naples, FL) is a nonabsorbable, polyester suture with a UHMWPE multifilament core and a braided polyester jacket. The nonbraided core resists elongation and is further protected by the polyester 

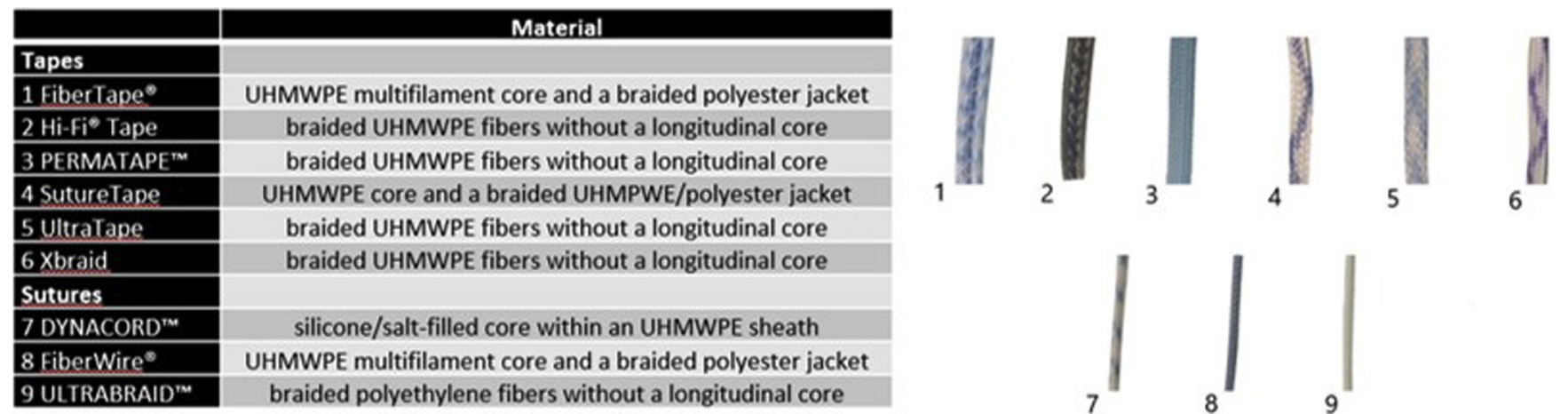

UHMWPE: ultra-high molecular weight polyethylene

Fig 1. Suture materials tested (6 tapes and 3 sutures) and their material composition.

jacket. Recently, No. 2 Dynacord suture (DePuy Mitek, Raynham, MA) was introduced, and less tendon cut through was found compared with FiberWire. ${ }^{15}$ Dynacord incorporates a silicone- and salt-filled core within a UHMWPE sheath. ${ }^{15}$ Another popular high-strength suture is Ultrabraid (Smith \& Nephew, Andover, MA), which has previously been shown to be less abrasive than FiberWire. ${ }^{16}$ Ultrabraid has braided UHMWPE fibers without a longitudinal core.

Over the past decade, tape-type sutures gained in popularity with promising reports in the literature. ${ }^{17-19}$ FiberTape (Arthrex) is an ultrahigh-strength 2-mmwide tape that incorporates the structure of FiberWire. It has shown 3 times higher stiffness and ultimate load to failure in comparison to FiberWire. ${ }^{20}$ Consequently, SutureTape (Arthrex) was introduced, which is a comparably thinner tape with a UHMWPE portion covered in a braided UHMWPE-polyester jacket, and also showed greater stiffness and ultimate load to failure than FiberWire. ${ }^{19}$ In knotted aRCR techniques, knots may be a source of potential subacromial irritation $^{21}$ and smaller knot sizes may be beneficial. Furthermore, desirable suture material properties provide sufficient hold in the tendon to avoid the common failure mode of suture-tissue cut through, besides sufficient mechanical strength to resist breakage with sufficient stiffness and knot security.

The purpose of this study was to assess the mechanical properties, tendon resistance to suture cutout, and knot size of a broad variety of high-strength sutures and tapes available for aRCR. We hypothesized that highstrength suture tapes would have significantly better mechanical properties than regular high-strength sutures. We further hypothesized that tapes would show greater tendon abrasiveness and larger knot sizes.

\section{Methods}

Ethical approval was obtained for this study (project No. 2018-00588).

\section{Experimental Design}

Nine different types of high-strength sutures and tapes for aRCR were studied; of these, 6 were tapes and 3 were sutures (Fig 1). The tapes used in this study were FiberTape, Hi-Fi Tape (ConMed Linvatec, Largo, FL), Permatape (DePuy Mitek), SutureTape, UltraTape (Smith \& Nephew), and XBraid TT $(2.0 \mathrm{~mm}$; Stryker Endoscopy, San Jose, CA). The sutures used were Dynacord, FiberWire, and Ultrabraid.

The study consisted of 2 parts: In the first part of the study, exclusive mechanical testing of all the types of suture material was performed (mechanical study). In the second part, the suture material was passed through an intact cadaveric human rotator cuff tendon and cyclic as well as load-to-failure testing was performed (cadaveric study).

\section{Experimental Setup}

Mechanical Study. Sutures were securely fixed around a dowel with a $20-\mathrm{cm}$ circumference, forming a suture loop using 7 square knots. The knots were all tied by 1 fellowship-trained orthopaedic surgeon (P.B.) performing more than 100 aRCR procedures per year. Furthermore, the knots were hand tied to prevent any potential differences or biases due to the use of instruments, as has been performed previously. ${ }^{10}$

Mechanical strain testing was performed using a material testing machine (Z010; Zwick/Roell, Ulm, Germany), which recorded the data with dedicated software (testExpert II; Zwick/Roell) and evaluated the data regarding load (in newtons) and displacement (in millimeters). Each suture loop construct was placed between a hook and a pin secured to the crosshead and base of the machine (Fig 2). The knot was placed so that it was between both dowel pins and not touching either one. Each suture loop was preloaded to $5 \mathrm{~N}$, and the initial crosshead displacement was recorded. Load and displacement data were recorded as the suture loops were loaded at a rate of $5 \mathrm{~mm} / \mathrm{second}$ until failure, 


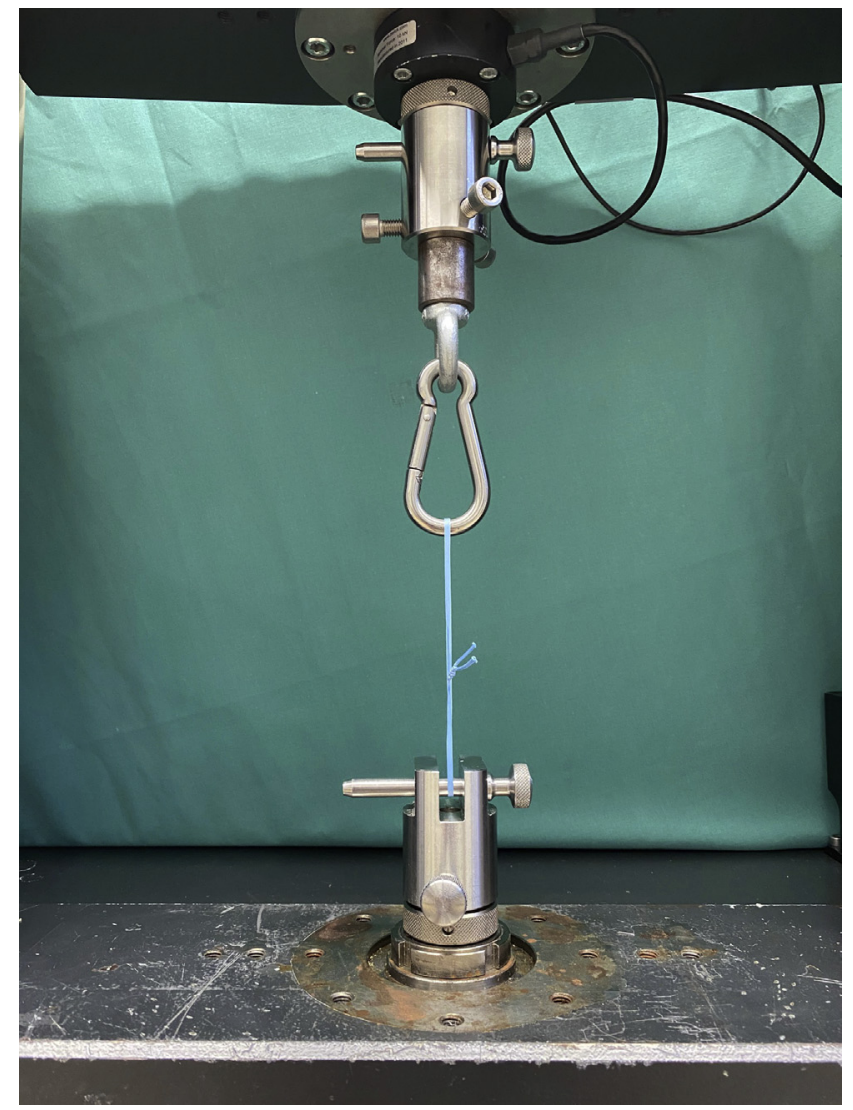

Fig 2. In the mechanical study part, each suture or tape loop construct was placed between a hook and a pin secured to the crosshead and base of the material testing machine.

similarly to other studies that recorded data at varying frequencies and at a rate of $1 \mathrm{~mm} / \mathrm{second}$. For each sample, we determined the ultimate load to failure; maximum load at 1, 2, and $3 \mathrm{~mm}$ of displacement; and mode of failure. Each of the 9 different sutures and tapes was tested 6 times.

Cadaveric Study. Two fellowship-trained orthopaedic surgeons (P.B. and L.E.) performed dissection, preparation, and repair after thawing of 18 fresh frozen $\left(-20^{\circ} \mathrm{C}\right)$ human shoulders (average age, 70.1 \pm 8.2 years) for 24 hours at room temperature. The supraspinatus and infraspinatus muscle and tendons were harvested from the specimens as a unit. The tendon unit was sharply detached from its insertion site at the greater tuberosity of the humerus and macroscopically assessed for rotator cuff integrity. Any rotator cuff tendon with a partial- or full-thickness tear was excluded. Specimens were kept moist with $0.9 \%$ saline solution during dissection, preparation, and mechanical testing. Seventy-two tests were performed on 18 rotator cuff units.

In each rotator cuff tendon unit, 4 possible stitch locations from anterior to posterior were tested. The rotator cable was identified on the articular side of the supraspinatus and infraspinatus tendons, and stitch positioning was determined as just medial to the rotator cable, as previously described by Wieser et al. ${ }^{10}$ Simple stitches, piercing the width of the tendon using 9 different high-strength sutures and tapes, were performed randomly in 4 different positions (from anterior to posterior) to minimize variability in technique (Fig 3). The distance between the stitches was about $1 \mathrm{~cm}$. Sutures were securely fixed to a 10,000-N load cell, forming a suture loop using 7 square knots. The muscle-tendon side of the specimen was wrapped in gauze and fastened between grooved jaws by bolts. Tendon thickness and knot height and width, as well as the distance of the suture to the myotendinous junction, were measured with a Vernier caliper $(0.01-\mathrm{mm}$ resolution). The average tendon thickness was $4.5 \pm 1.5 \mathrm{~mm}$ at the site where the tapes and sutures were pierced through the rotator cable, without a statistically significant difference between tapes and sutures $(P=.69)$. The average distance to the myotendinous junction was $13.8 \pm 5.1 \mathrm{~mm}$ $(P=.64)$. Separate cyclic and load-to-failure tests for each suture starting anteriorly and ending posteriorly were performed.

The investigations were performed using a material testing machine (Z010), which recorded the data with

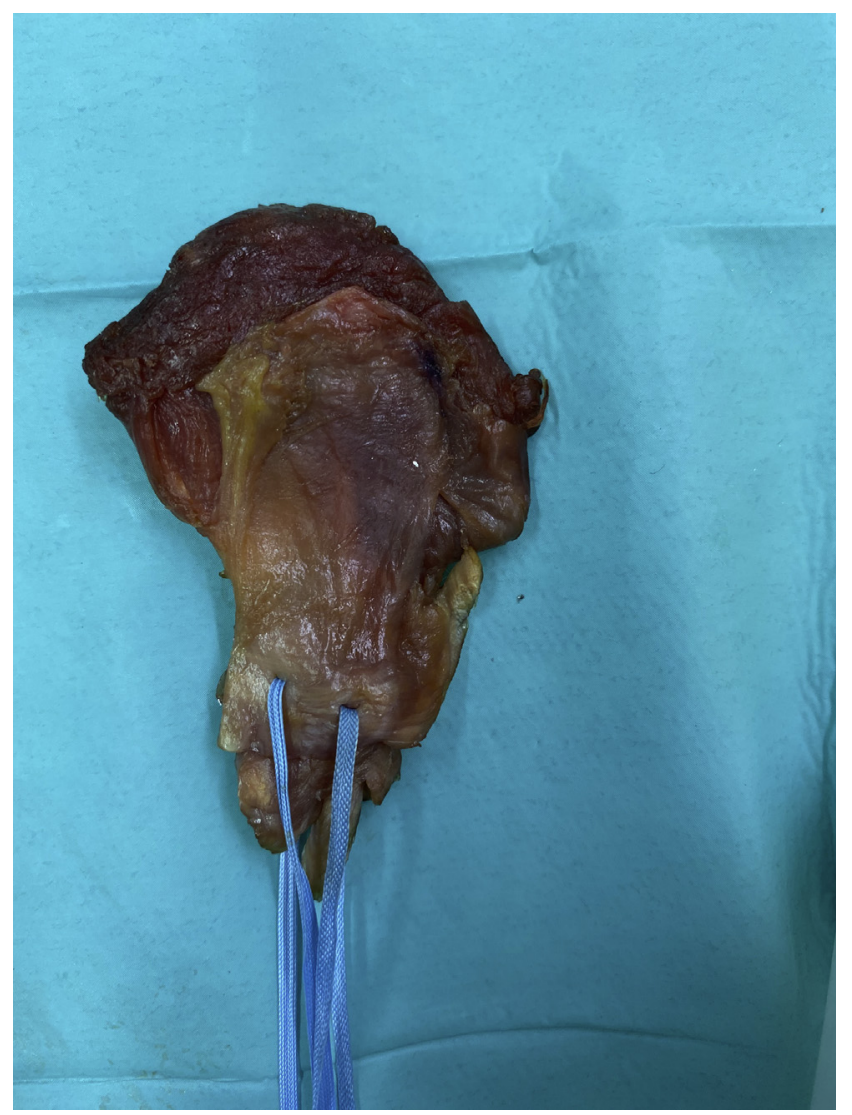

Fig 3. In the cadaveric study part, tapes or sutures were pierced just medial to the rotator cable of the rotator cuff tendon. 


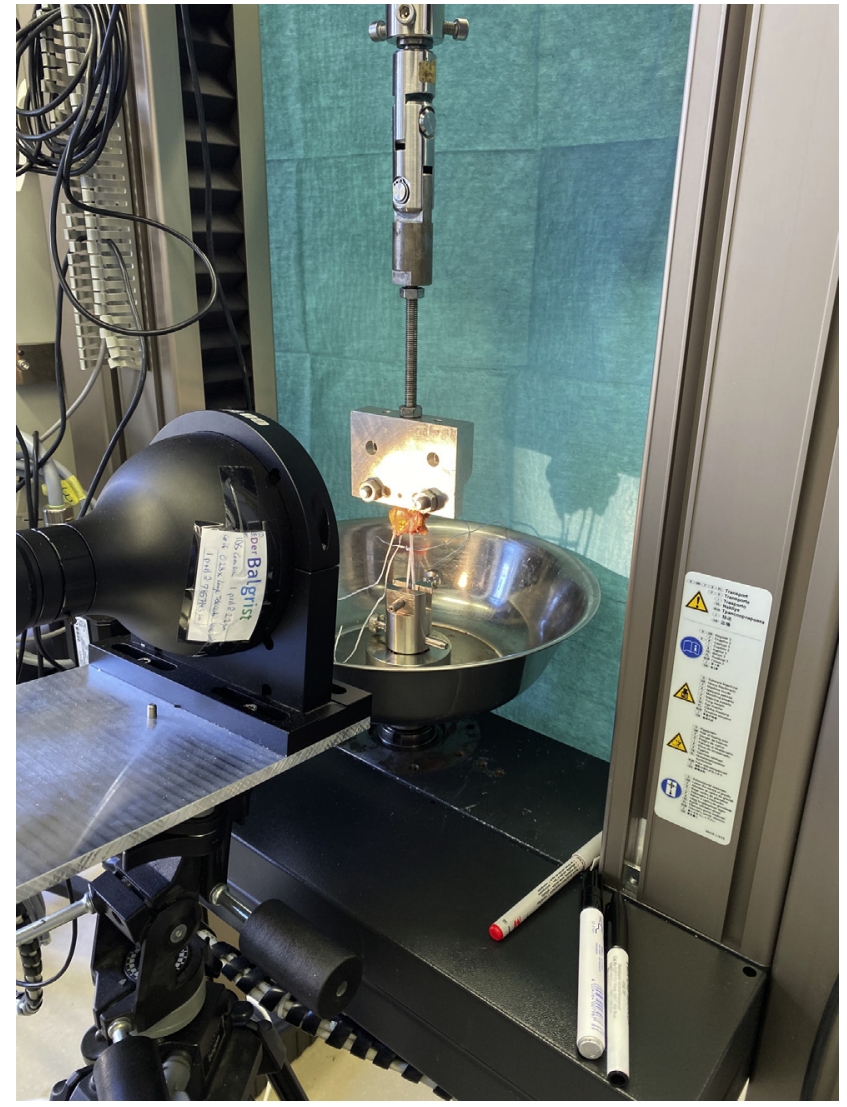

Fig 4. Experimental setup of cadaveric study part, in which cyclic loading and load-to-failure testing were performed in a material testing machine.

dedicated software (testExpert II) and evaluated the data regarding load (in newtons) and displacement (in millimeters); data were digitally recorded, and the deformation curve and mode of failure were documented (Fig 4). Displacement was assessed at 50 and $100 \mathrm{~N}$. After 40 cycles from 5 to $30 \mathrm{~N}$, a telecentric lens (Techspec Large Format 62-921; Edmund Optics, Barrington, $\mathrm{NJ}$ ), digital camera system (EOS M50; Canon, Tokyo, Japan), and ImageJ software (National Institutes of Health, Bethesda, MD) were used to measure any displacement of the suture as the suture cut through the tendon (Fig 5). Knot slippage was calculated as the difference in total displacement measured by the testing machine and knot displacement on the tendon, which was measured with the camera system.

\section{Statistical Analysis}

An a priori power analysis was performed based on the published data of Leishman and Chudik, ${ }^{19}$ who used 6 sutures per group to compare FiberWire suture with SutureTape in a testing model similar to that in our study. To detect a difference in ultimate load-to-failure testing $(327.2 \pm 15.4 \mathrm{~N}$ vs $257.4 \pm 12.2 \mathrm{~N})$ with a power of $90 \%$ and an $\alpha$ error of $5 \%$, the estimated sample size was only 2. Because most biomechanical suture studies have used 6 to 8 sutures per group, we decided to include 6 sutures in the mechanical study part and 8 sutures in the cadaveric study part.

The data were normally distributed per the ShapiroWilk test. Comparison of tapes versus sutures was performed using the unpaired Student $t$ test and l-way analysis of variance with Bonferroni adjustment when statistically significant. $P<.05$ was considered statistically significant, and all tests were 2 -tailed.

\section{Results}

\section{Mechanical Study}

There was a statistically significant difference between tapes and sutures regarding load for $3 \mathrm{~mm}$ of displacement $(201 \mathrm{~N}$ vs $83.9 \mathrm{~N}, P<.0001)$, displacement at $200 \mathrm{~N}$ ( $3.6 \mathrm{~mm}$ vs $6.6 \mathrm{~mm}, P<.0001)$, stiffness $(46.3 \mathrm{~N} / \mathrm{mm}$ vs $25 \mathrm{~N} / \mathrm{mm}, P<.0001)$, ultimate load to failure (509.2 N vs $288.4 \mathrm{~N}, P<.0001)$, and knot height (7.4 mm vs $5.6 \mathrm{~mm}, P<.0001$ ) but not displacement at failure (10.8 mm vs $8.7 \mathrm{~mm}, P=.27)$. The average ultimate load to failure of all 9 tested sutures and tapes was $435 \pm 174.5 \mathrm{~N}$, with the highest load to failure for FiberTape $(805.5 \pm 36.1 \mathrm{~N})$ and the lowest load to failure for No. 2 FiberWire $(257.8 \pm 15.3 \mathrm{~N}, P<.0001)$. FiberTape also showed the highest load necessary for 3 $\mathrm{mm}$ of displacement $(376.2 \pm 19.1 \mathrm{~N})$ and the lowest displacement at a 200-N load $(2 \pm 0.1 \mathrm{~mm}$ ) (Fig 6). Permatape was found to have the highest stiffness $(58.5 \pm 5.3 \mathrm{~N} / \mathrm{mm})$, whereas Dynacord had the lowest stiffness $(9 \pm 0.5 \mathrm{~N} / \mathrm{mm}, P<.0001)$. Dynacord also had the lowest load needed for $3 \mathrm{~mm}$ of displacement $(19.1 \pm 1.8 \mathrm{~N})$ and the lowest displacement at a $200-\mathrm{N}$ load $(10 \pm 0.6 \mathrm{~mm})$. SutureTape had the least displacement at failure $(5.9 \pm 0.4 \mathrm{~mm})$ of all sutures and tapes tested, with XBraid TT showing the highest displacement $(25.6 \pm 5.8 \mathrm{~mm}, P<.0001)$. Detailed results are listed in Tables 1 and 2 .

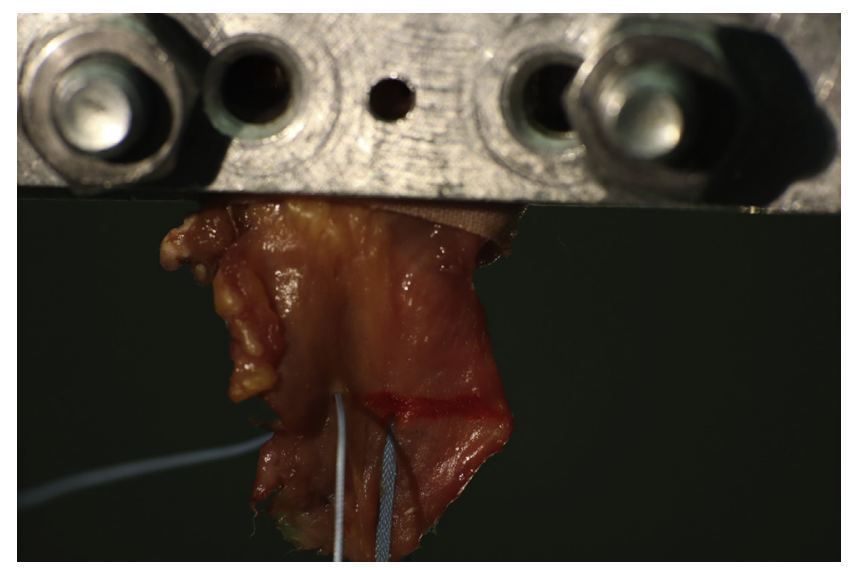

Fig 5. Displacement assessment in cadaveric study part. Before and after 40 cycles from 5 to $30 \mathrm{~N}$, cut through of the suture material into the tendon was measured using a telecentric lens, a digital camera system, and ImageJ software. 


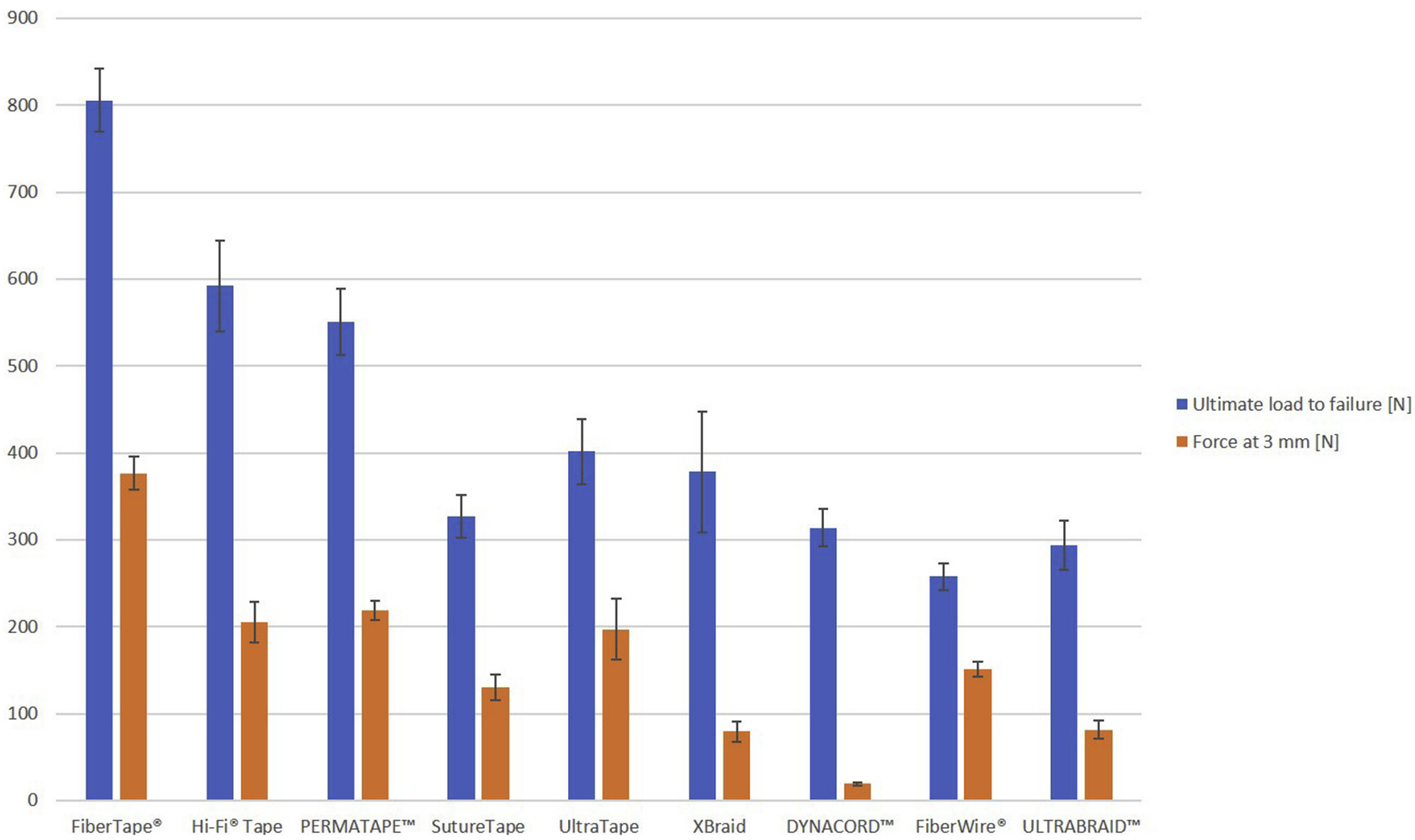

Fig 6. Ultimate load to failure (in newtons) and force necessary for $3 \mathrm{~mm}$ of displacement (in newtons) of all 9 sutures and tapes tested in the mechanical study part.

\section{Cadaveric Study}

The failure mode was tendon cut through $(98.6 \%)$ in all cases except in $1(1.4 \%)$, in which a FiberWire suture ruptured close to the knot at a failure load of 285 $\mathrm{N}$. We did not observe any significant knot slippage $(0.18 \pm 0.86 \mathrm{~mm}$ for tapes vs $0.11 \pm 0.57 \mathrm{~mm}$ for sutures, $P=.75$ ).

A statistically significant difference between tapes and sutures was found regarding load for $3 \mathrm{~mm}$ of displacement ( $55.3 \mathrm{~N}$ vs $43.6 \mathrm{~N}, P=.029)$, stiffness (20.4 $\mathrm{N} / \mathrm{mm}$ vs $16.8 \mathrm{~N} / \mathrm{mm}, P=.029)$, knot height ( $7.6 \mathrm{~mm}$ vs $6.3 \mathrm{~mm}, P=.007)$, and knot width $(2.3 \mathrm{~mm}$ vs $1.7 \mathrm{~mm}$, $P<.0001)$. There was no statistically significant difference between tapes and sutures for displacement at $50 \mathrm{~N}$ (2.6 $\mathrm{mm}$ vs $3.1 \mathrm{~mm}, P=.113$ ), displacement at $100 \mathrm{~N}$ (6.2 $\mathrm{mm}$ vs $7.1 \mathrm{~mm}, P=.257$ ), and ultimate load to failure (152.6 N vs $152.7 \mathrm{~N}, P=.996)$.

The average ultimate load to failure of all 9 sutures and tapes tested in tendons was $152.6 \pm 63.1 \mathrm{~N}$, with FiberTape showing the highest load to failure (178 \pm $50.5 \mathrm{~N})$ and UltraTape showing the lowest $(103.8 \pm 37.2$ $\mathrm{N}, P=.74)$. FiberTape also showed the highest stiffness $(26.1 \pm 7.6 \mathrm{~N} / \mathrm{mm})$, lowest cyclic displacement $(0.43 \pm$ $0.38 \mathrm{~mm})$, highest load necessary for $3 \mathrm{~mm}$ of displacement $(84.9 \pm 29.4 \mathrm{~N})$, and lowest displacement at $50-\mathrm{N}(1.9 \pm 0.7 \mathrm{~mm})$ and $100-\mathrm{N}(4.5 \pm 3.2 \mathrm{~mm})$ loads. In addition, FiberTape had the highest knot height $(9.5 \pm 1.3 \mathrm{~mm})$ and knot width $(3.8 \pm 0.7 \mathrm{~mm})$ measured compared with SutureTape, which had the lowest knot height $(5.6 \pm 0.7 \mathrm{~mm}, P<.0001)$ and, together with FiberWire and Ultrabraid, had the lowest knot width $(1.6 \pm 0.3 \mathrm{~mm}, P<.0001)$. XBraid TT had the lowest stiffness $(14.1 \pm 3.2 \mathrm{~N} / \mathrm{mm}, P=.013)$, highest cyclic displacement $(1.03 \pm 0.57 \mathrm{~mm}, P=$ not significant), and highest displacement at a 50-N load (3.7 \pm 1.1 $\mathrm{mm}, P=.02)$. Dynacord had the highest displacement at a $100-\mathrm{N}$ load $(8.8 \pm 3.3 \mathrm{~mm}, P=$ not significant $)$. Detailed results are listed in Tables 3 and 4 .

\section{Discussion}

The main finding of this biomechanical analysis was that tapes showed superior biomechanical characteristics both in the dry-laboratory testing setup and on in vitro rotator cuff tendon testing regarding stiffness

Table 1. Comparison of Results of Cyclic and Load-to-Failure Testing of High-Strength Sutures and Tapes (Mechanical Study Part)

\begin{tabular}{lccc}
\hline \multicolumn{1}{c}{ Parameter } & $\begin{array}{c}\text { Tapes } \\
(\mathrm{n}=36)\end{array}$ & $\begin{array}{c}\text { Sutures } \\
(\mathrm{n}=18)\end{array}$ & $P$ Value \\
\hline Stiffness, N/mm & $46 \pm 13.4$ & $25 \pm 14.2$ & $<.0001$ \\
Force at $3 \mathrm{~mm}, \mathrm{~N}$ & $201 \pm 95.3$ & $84 \pm 56.0$ & $<.0001$ \\
Displacement at $200 \mathrm{~N}, \mathrm{~mm}$ & $3.6 \pm 1.53$ & $6.6 \pm 2.60$ & $<.0001$ \\
Ultimate load to failure, $\mathrm{N}$ & $509 \pm 170.1$ & $288 \pm 31.7$ & $<.0001$ \\
Displacement at failure, $\mathrm{mm}$ & $10.8 \pm 7.54$ & $8.7 \pm 2.99$ & .157 \\
\hline
\end{tabular}

NOTE. Data are presented as mean \pm standard deviation. 
Table 2. Results of Cyclic and Load-to-Failure Testing (Mechanical Study Part) of 9 Different High-Strength Sutures and Tapes

\begin{tabular}{|c|c|c|c|c|c|c|c|c|c|c|c|}
\hline \multirow[b]{2}{*}{ Product } & \multirow[b]{2}{*}{$\mathrm{N}$} & \multicolumn{2}{|c|}{ Stiffness, $\mathrm{N} / \mathrm{mm}$} & \multicolumn{2}{|c|}{ Force at $3 \mathrm{~mm}, \mathrm{~N}$} & \multicolumn{2}{|c|}{$\begin{array}{r}\text { Displacement } \\
\text { at } 200 \mathrm{~N}, \mathrm{~mm} \\
\end{array}$} & \multicolumn{2}{|c|}{ Ultimate Load to Failure, $\mathrm{N}$} & \multicolumn{2}{|c|}{ Displacement at Failure, $\mathrm{mm}$} \\
\hline & & Mean & SD & Mean & SD & Mean & SD & Mean & SD & Mean & SD \\
\hline Hi-Fi Tape & 6 & 56 & 3.2 & 205 & 23.2 & 3.2 & 0.74 & 592 & 52.4 & 25.6 & 5.79 \\
\hline Permatape & 6 & 58 & 5.3 & 219 & 11.0 & 2.8 & 0.12 & 551 & 38.1 & 7.4 & 1.66 \\
\hline SutureTape & 6 & 37 & 2.3 & 130 & 14.6 & 4.2 & 0.34 & 327 & 24.7 & 5.9 & 0.35 \\
\hline UltraTape & 6 & 54 & 4.9 & 197 & 35.0 & 5.7 & 0.39 & 402 & 37.6 & 5.9 & 1.11 \\
\hline Dynacord & 6 & 9 & 0.5 & 19 & 1.8 & 10.0 & 0.58 & 314 & 21.6 & 12.4 & 1.47 \\
\hline FiberWire & 6 & 42 & 4.4 & 151 & 9.0 & 4.1 & 0.41 & 258 & 15.3 & 6.0 & 0.98 \\
\hline Ultrabraid & 6 & 24 & 0.9 & 82 & 10.6 & 5.7 & 0.39 & 294 & 28.3 & 7.6 & 0.66 \\
\hline Total & 54 & 29 & 2.3 & 162 & 100.5 & 4.6 & 2.42 & 436 & 174.5 & 10.1 & 6.43 \\
\hline
\end{tabular}

SD, standard deviation.

and the load needed for $3 \mathrm{~mm}$ of displacement (clinical failure). However, as expected, tapes also had a higher average knot height and knot width.

FiberTape showed the best mechanical properties for various tested parameters, such as stiffness, cyclic displacement, load necessary for $3 \mathrm{~mm}$ of displacement, and displacement at both 50- and 100-N loads in the tendon testing setup. However, FiberTape also had the largest knot size. The clinical relevance of potential subacromial irritation caused by this higher amount of knot volume has not been proved so far, and the mechanical superiority of FiberTape may outweigh this potential yet undescribed disadvantage. Thus, animal studies suggest that nonabsorbable bulky knots may migrate, cause chronic inflammation, and potentially weaken tendon-to-bone healing. ${ }^{21}$

Suture-tendon cut through is usually considered the weakest link of the tendon-to-bone RCR and therefore one of the most important reasons for failure in aRCR, ${ }^{12,22}$ and abrasiveness of the suture material used may be an essential biomechanical factor. ${ }^{15,16,23}$ Contrary to observations of previously published studies, ${ }^{15,17,19,23}$ we could not find significantly less tendon cut through of tapes versus sutures. However, our findings may be related to the high number of tapes

Table 3. Comparison of Results of Cyclic and Load-to-Failure Testing of High-Strength Sutures and Tapes in Human Rotator Cuff Tendons (Cadaveric Study Part)

\begin{tabular}{lrrc}
\hline \multicolumn{1}{c}{ Parameter } & $\begin{array}{c}\text { Tapes } \\
(\mathrm{n}=48)\end{array}$ & $\begin{array}{c}\text { Sutures } \\
(\mathrm{n}=24)\end{array}$ & $P$ Value \\
\hline Stiffness, N/mm & $20.4 \pm 7.6$ & $16.9 \pm 5.1$ & .029 \\
Cyclic displacement, mm & $0.8 \pm 0.65$ & $0.6 \pm 0.33$ & .586 \\
Force at 3 mm of displacement, N & $55.3 \pm 25.4$ & $43.6 \pm 16.8$ & .029 \\
Displacement at 50 N, mm & $2.6 \pm 1.13$ & $3.1 \pm 1.01$ & .113 \\
Displacement at 100 N, mm & $6.2 \pm 2.56$ & $7.1 \pm 2.48$ & .257 \\
Ultimate load to failure, N & $153 \pm 61.5$ & $153 \pm 67.5$ & .996 \\
Knot height, mm & $7.6 \pm 1.55$ & $6.4 \pm 1.63$ & .007 \\
Knot width, mm & $2.3 \pm 0.82$ & $1.7 \pm 0.31$ & .001 \\
\hline
\end{tabular}

NOTE. Data are presented as mean \pm standard deviation. tested in this study, which have shown considerably and significantly different results. Whereas FiberTape has shown the least amount of cycling displacement $(0.4 \mathrm{~mm})$ of all sutures and tapes tested, another tape (XBraid TT) had the highest cyclic displacement (1 mm). Therefore, individual suture material analyses were found to be more relevant in the assessment of abrasiveness than comparing general tape and suture groups. Furthermore, the different knot size and strength can be well explained by the different sizes of the tapes and sutures tested. For example, FiberTape has a diameter of $2 \mathrm{~mm}$, making it larger than any other suture material tested. An interesting finding was that a tape-type suture (SutureTape) showed the lowest knot volume in our study.

Failure analysis in the second part of the study confirmed that the mechanical strength of all suture materials tested is high enough because the weak point, as well as the typical failure mechanism, is tendon cut through of the suture material. ${ }^{12,22}$ The average failure loads were comparable between tapes and sutures; however, interindividual ultimate failure loads were also significantly different in this part of the study. Whereas a variety of tapes and a suture (FiberTape, SutureTape, FiberWire, and Permatape) had similar high failure loads, another tape (UltraTape) showed a significantly lower load to failure. Various parameters such as tendon quality, stitch positioning within the rotator cable, and abrasiveness of the suture material may influence these results. However, meticulous attention was paid to diminish the influence of the first 2 possible causes because the tendon location for stitch positioning was randomized, the tendon thickness and distance to the myotendinous junction were measured, and no differences were found regarding the suture material groups.

It is interesting to note that the stiffness values in our study $(46 \pm 13.4 \mathrm{~N} / \mathrm{mm}$ for tapes vs $25 \pm 14.2 \mathrm{~N} / \mathrm{mm}$ for sutures, $P<.0001$ ) are substantially higher than the values published by Leishman and Chudik $^{19}$ for 


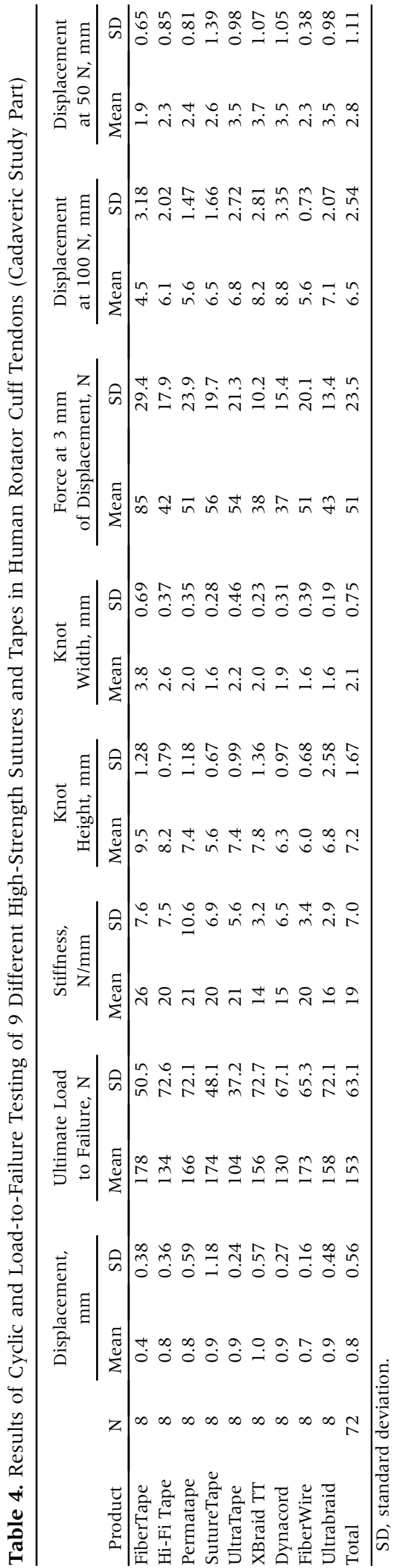

FiberWire $(2.8 \pm 0.3 \mathrm{~N} / \mathrm{mm})$ and SutureTape $(5.4 \pm 0.3$ $\mathrm{N} / \mathrm{mm}$ ). We can only hypothesize that the insufficient stiffness in their study is related to the study method used.

\section{Limitations}

A limitation of this study is that we did not examine the influence of different types of RCR techniques in a tendon-to-bone repair model, such as single- versus double-row or suture-bridge repair, as well as the use of knotted versus knotless anchors. There would have been too many variables that would have weakened the main goal of the study: to independently evaluate the actual biomechanical properties of different highstrength sutures and tapes. We decided to use simple stitches, as published in similar previous biomechanical studies. ${ }^{10}$ However, this is not a common method of aRCR today and therefore is a limitation. Furthermore, the results of our study should be analyzed in light of the fact that our biomechanical model comprised intact and not degenerated rotator cuff tendons, a factor known to significantly influence suture behavior and therefore tendon cut through. ${ }^{1}$ Moreover, we did not analyze the influence of testing temperature, ${ }^{24}$ as well as suture integration in living tissue. ${ }^{25}$ Another weakness is that we did not include all tapes and sutures that are available on the market for aRCR. However, we tried to include as many tapes as possible and decided to include 3 sutures that have shown good biomechanical data in the literature previously, with No. 2 FiberWire probably being the gold standard for many years. A further weakness of this in vitro study is that we did not perform the tests in an aqueous test setup, which could have had a potential beneficial effect on the results of the Dynacord sutures. ${ }^{15}$ However, we decided to test all tapes and sutures under standardized conditions to provide adequate comparability of all products, as performed in previous biomechanical studies. ${ }^{6,17,19,26}$ To reduce the risk of operator bias, all knots were tied in a standardized open fashion by an experienced shoulder surgeon. This strong knot-tying technique was chosen to prevent suture slippage because this occurs quite frequently in arthroscopic techniques. ${ }^{27}$

\section{Conclusions}

Biomechanical in vitro testing showed that highstrength suture tapes compared with regular highstrength sutures have significantly better mechanical properties in both dry-laboratory testing and human cadaveric rotator cuff tendon pullout testing. FiberTape outperformed the other tapes and the sutures used in this analysis. Nonetheless, differences in tendon testing appeared to be less substantial than in dry-laboratory testing, and FiberTape had the highest knot height and width. 


\section{References}

1. Chung SW, Kim JY, Yoon JP, Lyu SH, Rhee SM, Oh SB. Arthroscopic repair of partial-thickness and small fullthickness rotator cuff tears: Tendon quality as a prognostic factor for repair integrity. Am J Sports Med 2015;43: 588-596.

2. Denard PJ, Burkhart SS. Techniques for managing poor quality tissue and bone during arthroscopic rotator cuff repair. Arthroscopy 2011;27:1409-1421.

3. Meyer DC, Farshad M, Amacker NA, Gerber C, Wieser K. Quantitative analysis of muscle and tendon retraction in chronic rotator cuff tears. Am J Sports Med 2012;40: 606-610.

4. Wieser K, Joshy J, Filli L, et al. Changes of supraspinatus muscle volume and fat fraction after successful or failed arthroscopic rotator cuff repair. Am J Sports Med 2019;47: 3080-3088.

5. Baleani M, Schrader S, Veronesi CA, Rotini R, Giardino R, Toni A. Surgical repair of the rotator cuff: A biomechanical evaluation of different tendon grasping and bone suture fixation techniques. Clin Biomech (Bristol, Avon) 2003;18:721-729.

6. Barber FA, Herbert MA, Richards DP. Sutures and suture anchors: Update 2003. Arthroscopy 2003;19:985-990.

7. Meyer DC, Bachmann E, Ladermann A, Lajtai G, Jentzsch T. The best knot and suture configurations for high-strength suture material. An in vitro biomechanical study. Orthop Traumatol Surg Res 2018;104:1277-1282.

8. Noyes MP, Ladermann A, Denard PJ. Functional outcome and healing with a load-sharing rip-stop repair compared with a single-row repair for large and massive rotator cuff tears. Arthroscopy 2019;35:2295-2300.

9. Takeuchi Y, Sugaya H, Takahashi N, et al. Repair integrity and retear pattern after arthroscopic medial knot-tying after suture-bridge lateral row rotator cuff repair. Am J Sports Med 2020;48:2510-2517.

10. Wieser K, Rahm S, Farshad M, Ek ET, Gerber C, Meyer DC. Stitch positioning influences the suture hold in supraspinatus tendon repair. Knee Surg Sports Traumatol Arthrosc 2013;21:1587-1592.

11. Cole BJ, ElAttrache NS, Anbari A. Arthroscopic rotator cuff repairs: An anatomic and biomechanical rationale for different suture-anchor repair configurations. Arthroscopy 2007;23:662-669.

12. Cummins CA, Murrell GA. Mode of failure for rotator cuff repair with suture anchors identified at revision surgery. J Shoulder Elbow Surg 2003;12:128-133.

13. Chan KC, Burkhart SS, Thiagarajan P, Goh JC. Optimization of stacked half-hitch knots for arthroscopic surgery. Arthroscopy 2001;17:752-759.

14. Wust DM, Meyer DC, Favre P, Gerber C. Mechanical and handling properties of braided polyblend polyethylene sutures in comparison to braided polyester and monofilament polydioxanone sutures. Arthroscopy 2006;22: 1146-1153.
15. Owens BD, Algeri J, Liang V, DeFroda S. Rotator cuff tendon tissue cut-through comparison between 2 hightensile strength sutures. J Shoulder Elbow Surg 2019;28: 1897-1902.

16. Williams JF, Patel SS, Baker DK, Schwertz JM, McGwin G, Ponce BA. Abrasiveness of high-strength sutures used in rotator cuff surgery: Are they all the same? J Shoulder Elbow Surg 2016;25:142-148.

17. Gnandt RJ, Smith JL, Nguyen-Ta K, McDonald L, LeClere LE. High-tensile strength tape versus high-tensile strength suture: A biomechanical study. Arthroscopy 2016;32:356-363.

18. Huntington L, Coles-Black J, Richardson M, et al. The use of suture-tape and suture-wire in arthroscopic rotator cuff repair: A comparative biomechanics study. Injury 2018;49:2047-2052.

19. Leishman DJ, Chudik SC. Suture tape with broad full-width core versus traditional round suture with round core: A mechanical comparison. Arthroscopy 2019;35:2461-2466.

20. Bisson LJ, Manohar LM. A biomechanical comparison of the pullout strength of No. 2 FiberWire suture and 2-mm FiberWire tape in bovine rotator cuff tendons. Arthroscopy 2010;26:1463-1468.

21. Sun Y, Kwak JM, Kholinne E, Tan J, Koh KH, Jeon IH. Nonabsorbable suture knot on the tendon affects rotator cuff healing: A comparative study of the knots on tendon and bone in a rat model of rotator cuff tear. Am J Sports Med 2019;47:2809-2815.

22. Bisson LJ, Manohar LM, Wilkins RD, Gurske-Deperio J, Ehrensberger MT. Influence of suture material on the biomechanical behavior of suture-tendon specimens: A controlled study in bovine rotator cuff. Am J Sports Med 2008;36:907-912.

23. Ono Y, Joly DA, Thornton GM, Lo IKY. Mechanical and imaging evaluation of the effect of sutures on tendons: Tape sutures are protective to suture pulling through tendon. J Shoulder Elbow Surg 2018;27:1705-1710.

24. Brucker PU, Favre P, Puskas GJ, von Campe A, Koch PP, Meyer DC. Influence of test temperature on biomechanical properties of all-inside meniscal repair devices and inside-out meniscus sutures-Evaluation of an isolated distraction loading, worst-case scenario. Clin Biomech (Bristol, Avon) $2011 ; 26: 749-753$.

25. Meyer DC, Hasler A, Wyss S, et al. Mechanisms of suture integration in living tissue: Biomechanical and histological in vivo analysis in sheep. Orthopedics 2019;42:168-175.

26. Deranlot J, Maurel N, Diop A, et al. Abrasive properties of braided polyblend sutures in cuff tendon repair: An in vitro biomechanical study exploring regular and tape sutures. Arthroscopy 2014;30:1569-1573.

27. Pedowitz RA, Nicandri GT, Angelo RL, Ryu RK, Gallagher AG. Objective assessment of knot-tying proficiency with the Fundamentals of Arthroscopic Surgery Training program workstation and knot tester. Arthroscopy 2015;31:1872-1879. 